\title{
Membrane progesterone receptor a (mPRa) (4) enhances hypoxia-induced vascular endothelial growth factor secretion and angiogenesis in lung adenocarcinoma through STAT3 signaling
}

\author{
Zhi Xia ${ }^{1}$, Jian Xiao ${ }^{1}$, Ziyu Dai $^{1}$ and Qiong Chen ${ }^{1,2^{*}(\mathbb{D}}$
}

\begin{abstract}
Lung cancer remains a huge challenge to public health because of its high incidence and mortality, and lung adenocarcinoma (LUAD) is the main subtype of lung cancer. Hypoxia-induced vascular endothelial growth factor (VEGF) release and angiogenesis have been regarded as critical events in LUAD carcinogenesis. In the present study, membrane progesterone receptor a (mPRa) is deregulated within LUAD tissue samples; increased mPRa contributes to a higher microvessel density (MVD) in LUAD tissues. mPRa knockdown in A549 and PC-9 cells significantly inhibited STAT3 phosphorylation, as well as HIF1 a and VEGF protein levels, decreasing cancer cell migration and invasion. The in vivo xenograft model further confirmed that mPRa enhanced the aggressiveness of LUAD cells. Furthermore, mPRa knockdown significantly inhibited hypoxia-induced upregulation in HIF1a and VEGF levels, as well as LUAD cell migration and invasion. Under the hypoxic condition, conditioned medium (CM) derived from mPRa knockdown A549 cells, namely si-mPRa-CM, significantly inhibited HUVEC migration and tube formation and decreased VEGF level in the culture medium. In contrast, CM derived from mPRa-overexpressing A549 cells, namely mPRa-CM, further enhanced HUVEC migration and tube formation and increased VEGF level under hypoxia, which was partially reversed by STAT3 inhibitor Stattic. In conclusion, in LUAD cells, highly expressed mPRa enhances the activation of CAMP/JAK/ STAT3 signaling and increases HIF1a-induced VEGF secretion into the tumor microenvironment, promoting HUVEC migration and tube formation under hypoxia.
\end{abstract}

Keywords: Lung adenocarcinoma, Membrane progesterone receptor a (mPRa), Vascular endothelial growth factor (VEGF), Hypoxia, Angiogenesis, STAT3 signaling

\section{Introduction}

Lung cancer is one of the most commonly seen cancers with the second-highest incidence rate among men and women globally. Lung cancer mortality ranks first

*Correspondence: qiongch@163.com

1 Department of Geriatrics, Respiratory Medicine, Xiangya Hospital, Central South University, Changsha, Hunan, China

Full list of author information is available at the end of the article among all cancers [1-3]. NSCLC (non-small cell lung cancer) accounts for approximately $85 \%$ of lung cancers, and LUAD (lung adenocarcinoma) is the most common subtype of NSCLC [2]. As the high-throughput sequencing technique develops, gene deregulation in LUAD has been gradually identified. Thus, further investigating the specific role of these deregulated genes in LUAD might provide an in-depth understanding of the occurrence, development, and treatment of LUAD. original author(s) and the source, provide a link to the Creative Commons licence, and indicate if changes were made. The images or other third party material in this article are included in the article's Creative Commons licence, unless indicated otherwise in a credit line to the material. If material is not included in the article's Creative Commons licence and your intended use is not permitted by statutory regulation or exceeds the permitted use, you will need to obtain permission directly from the copyright holder. To view a copy of this licence, visit http://creativecommons.org/licenses/by/4.0/. The Creative Commons Public Domain Dedication waiver (http://creativeco mmons.org/publicdomain/zero/1.0/) applies to the data made available in this article, unless otherwise stated in a credit line to the data. 
Unlike lung squamous cell carcinoma, which is prone to occur in men and is closely related to smoking [4], LUAD is often in women who do not smoke [5, 6]. Even with LUAD, male and female patients have significant differences in treatment response and prognosis [7, 8]. Thus, it is reasonable to hypothesize that the onset and development of LUAD might be related to female sex hormones, mainly including estrogen and progesterone. Previous studies indicate that the receptors of estrogen, ER $\alpha$ (estrogen receptor $\alpha$ ) and ER $\beta$ (estrogen receptor $\beta$ ), appear to be expressed within pulmonary cancer/ LUAD, and both can mediate the oncogenic role of estrogen in lung cancer or act as oncogenic factors themselves [9-11]. As for progesterone, in addition to the canonical progesterone receptor (PR), membrane progesterone receptors (mPRs) attract more and more attention because of their potential role in cancers. One of the $\mathrm{mPRs}, \mathrm{mPR} \alpha$, is expressed within various types of cancer cells, such as breast carcinoma cells [12], ovarian cancer cells [13], astrocytoma cells [14], and glioblastoma cells [15]. $\mathrm{mPR} \alpha$ has been reported to promote the development of breast cancer [12, 16, 17]. Although $\mathrm{mPR} \alpha$ expression is upregulated in LUAD tissues, according to data from GEPIA (Gene Expression Profiling Interactive Analysis), the independent role of $\mathrm{mPR} \alpha$ in LUAD remains unclear.

Angiogenesis, the sprouting of capillaries from preexisting blood vessels, is crucial for solid tumor cell growth, invasion, and metastasis $[18,19]$. In an oxygen-deficient environment, the hypoxia-inducible factor (HIF1 $\alpha$ ) is a key transcriptional mediator of the response to hypoxic conditions. HIF1 $\alpha$ regulates the secretion of several angiogenic factors, including VEGF (vascular endothelial growth factor), from tumor cells into cancer microenvironment [20], subsequently promoting angiogenesis. Moreover, several signaling pathways are involved in tumor neovascularization. For example, exogenous IGF-1 leads to the activation of IGF1R and STAT3 and upregulates the protein contents of HIF $1 \alpha$ and the transcription activity of HIF1, resulting in VEGF release and angiogenesis [21]. CXCR4 enhances tumor blood vessel formation within gastric carcinoma through JAK2/STAT3 activation [22]. Notably, increased activity of STAT3 enhances the activity of HIF1 $\alpha$, and STAT3 is another factor able to bind to HIF1 $\alpha$ promoter within transformed cell lines and growing tumors [23]. However, whether $\mathrm{mPR} \alpha$ is involved in the JAK/STAT3 signaling-induced activation of HIF $1 \alpha /$ VEGF in LUAD is unclear.

Progesterone signaling initiated at the plasma membrane via $G$ protein activation in numerous target cells is mediated by $\mathrm{mPR} \alpha$ [24-28]. A G protein-binding domain has been partially characterized on the third intracellular loop of $m P R \alpha$ at a similar position to that shown to be important for $\mathrm{G}$ protein signaling in $\mathrm{G}$ protein-coupled receptors [28]. Progesterone has been shown to activate $G$ protein via mPRs within many vertebrate cellular types [24, 28-31]. The fish mPR $\alpha$ is coupled to an inhibitory $\mathrm{G}$ protein, thereby mediating progesterone-dependent MAPK activation and inhibiting cAMP production [32]. In the lactotroph population, $\mathrm{mPR} \alpha$ can mediate the suppressive role of progesterone in the secretion of PRL via reduced cAMP levels and decreased TGF $\beta 1$ activation within the lactotroph population [33]. Thus, it's reasonable to hypothesize that $\mathrm{mPR} \alpha$ might affect hypoxia-induced angiogenesis in LUAD through cAMP/ JAK/STAT3 signaling and HIF1 $\alpha$-induced VEGF release.

The effects of mPR $\alpha$ on cancer cells' capacity to proliferate, migrate, and invade has been reported within glioblastoma cells [15]. Herein, $\mathrm{mPR} \alpha$ expression and microvessel density (MVD) within LUAD tissue samples were evaluated. $\mathrm{mPR} \alpha$ knockdown or overexpression was generated in LUAD cells, and the roles of $\mathrm{mPR} \alpha$ in cAMP concentrations, the protein levels of STAT3 signaling factors, HIF1 $\alpha$, and VEGF, and LUAD cell migration, invasion in vitro and tumor growth in vivo were investigated. As for hypoxia-induced angiogenesis, firstly, we exposed LUAD cells to a normoxic or hypoxic environment and examined the effects of $m P R \alpha$ knockdown on HIF $1 \alpha$ and VEGF protein levels, LUAD cell migration and invasion; secondly, culture medium derived from $\mathrm{mPR} \alpha$ knockdown or overexpressing LUAD cells was used for HUVEC (human umbilical vein endothelial cell) culture, and the cumulative tube length and cell migration ability of HUVECs were examined. In summary, we attempt to validate the specific effect and potential mechanism of $\mathrm{mPR} \alpha$ for hypoxia-induced angiogenesis in LUAD.

\section{Materials and methods Clinical sampling}

A total of 20 paired lung adenocarcinoma (LUAD) tissues and adjacent noncancerous tissues were obtained from patients diagnosed with LUAD and underwent surgical resection at Xiangya Hospital of Central South University with the informed consent signed. All samples were stored at $-80{ }^{\circ} \mathrm{C}$ or formalin-fixed and paraffin-embedded. All of the experimental procedures were performed under the Ethics Committee of Xiangya Hospital of Central South University (No.202009803).

\section{Cell lines}

Lung adenocarcinoma cell line PC-9 was obtained from Merck (90,071,810; Kenilworth, NJ, USA) and cultured in RPMI 1640 plus $2 \mathrm{mM}$ Glutamine and 10\% Fetal Bovine Serum (FBS; Invitrogen, Carlsbad, CA, USA). Lung adenocarcinoma cell line A549 (adenocarcinomic human alveolar basal epithelial cell line) was procured 
from ATCC (CCL-185; Manassas, VA, USA) and cultured in F-12 K Medium (30-2004; ATCC) plus 10\% FBS. HUVEC was procured from ATCC (PCS-100-010) and cultured in $\mathrm{EGM}^{\mathrm{TM}}$-2 Endothelial Cell Growth Medium (CC-3162; Lonza, Basel, Switzerland). All the cells were cultured at $37^{\circ} \mathrm{C}$ in $5 \% \mathrm{CO}_{2}$.

\section{Cell transfection and treatment}

$\mathrm{mPR} \alpha$ knockdown was generated in target cells by transducing mPR $\alpha$ t arget-specific siRNA (si-mPR $\alpha)$ synthesized by GenePharma (Shanghai, China). Scramble siRNAs were used as a negative control (si-NC). mPR $\alpha$ overexpression was generated by the transfection of $\mathrm{mPR} \alpha$-overexpressing vector $(\mathrm{mPR} \alpha)$ synthesized by GenePharma. The empty vector was used as a negative control (NC). Following the protocols, si-mPR $\alpha / s i-N C$ or $\mathrm{mPR} \alpha / \mathrm{NC}$ was transfected into LUAD cells (A549 and PC9), respectively, using lipofectamine 3000 (Invitrogen). The sequence of siRNA was listed in Additional file 2: Table S1.

For STAT3 inhibition, cells were treated with Stattic $(5 \mu \mathrm{M})$ for $24 \mathrm{~h}$. For hypoxia treatment, transfected LUAD cells and HUVECs were exposed to $1 \% \mathrm{O}_{2}$ for $24 \mathrm{~h}$ in a tri-gas incubator (SANYO, Japan).

\section{Polymerase chain reaction (PCR)-based analyses}

Total RNA was extracted, processed, and examined for the expression of target mRNA following the methods described previously [34]. mRNA expression was detected by SYBR green PCR Master Mix (Qiagen, Hilden, Germany) using $\beta$-actin (for mRNA examination) as an endogenous control. The data were processed using a $2^{-\triangle \Delta C T}$ method. The primers are listed in Additional file 2: Table S1.

\section{Immunohistochemical (IHC) staining}

Clinical and mice tumor tissue samples were sectioned into $5 \mu \mathrm{m}$-thick slices, deparaffinized in xylene, and rehydrated in a series of graded alcohols. The antigen retrieval was performed by immersing the slides in sodium citrate. The endogenous peroxidase was blocked by a 10-min incubation with $3 \% \mathrm{H}_{2} \mathrm{O}_{2}$. Next, the slices were incubated with primary antibody anti-mPR $\alpha$ (ab75508, Abcam, Cambridge, UK), anti-CD31 (11265-1-AP, Proteintech, Wuhan, China), ki-67 (27309-1-AP, Proteintech), or PCNA (10205-2-AP, Proteintech) overnight at $4{ }^{\circ} \mathrm{C}$, washed thrice by PBS, and incubated with horseradish peroxidase (HRP)-conjugated secondary antibody (ab205718, Abcam) for 30 min. Finally, the immunostaining was performed using a DAB (diaminobenzidine) Substrate Kit (ab64238; Abcam).

\section{Evaluation of microvessel density}

A total of 10 LUAD tissue samples were used for MVD assessment, 5 with relatively high mPRoexpression and 5 with relatively low $\mathrm{mPR} \alpha$ expression. Each section was examined at low magnification $(40 \times)$, the area with the highest vascular density (hot spot) was selected, and then observed at high magnification $(100 \times)$. CD31-positive vessels were counted in three to five hot spots, respectively. Only continuous, membranous staining was considered as positive. Any large microvessel with a lumen or any single, separated endothelial cell was given a count of one. The vessels were counted within the epithelium and at the epithelium/stroma edge.

\section{Immunoblotting}

Total protein was extracted, resolved on 10\% SDS-PAGE, and transferred onto polyvinylidene fluoride (PVDF) membranes. Non-specific bindings were blocked by incubation with $5 \%$ nonfat dry milk in Tris-buffered saline Tween (TBST) for $2 \mathrm{~h}$. After that, the membranes were probed with appropriate primary antibodies at $4{ }^{\circ} \mathrm{C}$ overnight, followed by another incubation with the corresponding secondary antibodies for $2 \mathrm{~h}$ at room temperature. The primary antibodies used are as follows: anti-mPR $\alpha$ (ab75508, Abcam), anti-STAT3 (10,253-2-AP; Proteintech, Wuhan, China), anti-p-STAT3 (ab76315, Abcam), anti-VEGF (66,828-1-Ig, Proteintech), antiHIF1 $\alpha$ (20,960-1-AP, Proteintech), and $\beta$-actin (endogenous control; 6008-1-Ig, Proteintech).

\footnotetext{
(See figure on next page.)

Fig. 1 Expression of mPRa in tissue samples. A The mRNA expression of mPRa in 483 lung adenocarcinoma (LUAD) tissue samples and 347 noncancerous tissue samples according to TCGA database. B Cases from the TCGA-LUAD database were divided into two groups using the best cutoff of mPRa expression. The correlation between mPRa expression and the overall survival in patients with LUAD was analyzed by KMPLOT (https://kmplot.com/analysis/). C The mRNA expression of mPRa was determined in 20 paired LUAD and adjacent noncancerous tissue samples using real-time PCR. D The protein content and distribution of mPRa were determined in LUAD and adjacent noncancerous tissue samples using immunohistochemical $(\mathrm{IHC})$ staining. E The protein content and distribution of mPRa were determined in LUAD and adjacent noncancerous tissue samples using Immunoblotting. F The CD31-MVD was determined in LUAD tissues samples with a high or low mPRa level. ${ }^{* *} P<0.01,{ }^{* * *} P<0.005$
} 

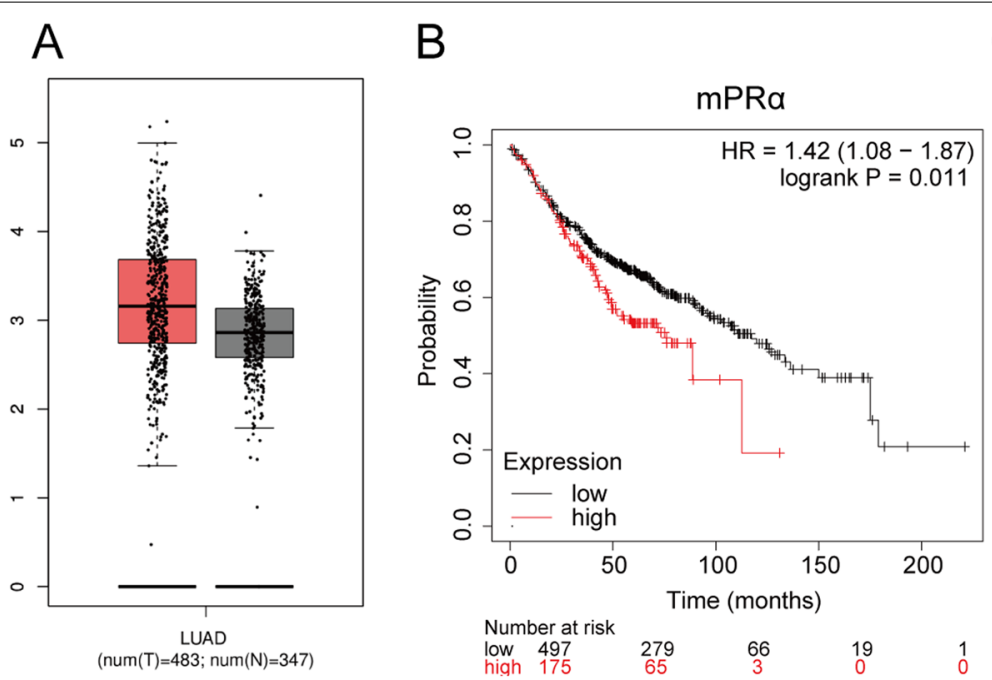

C

D

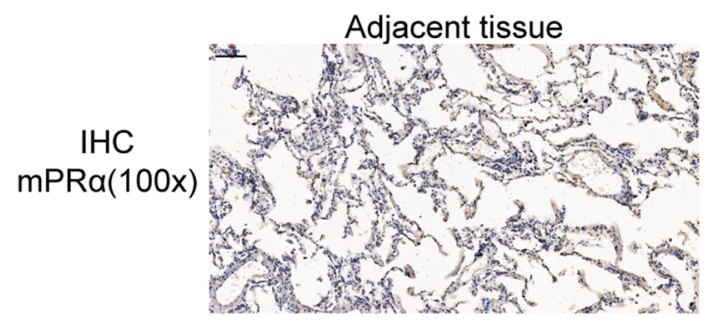

E
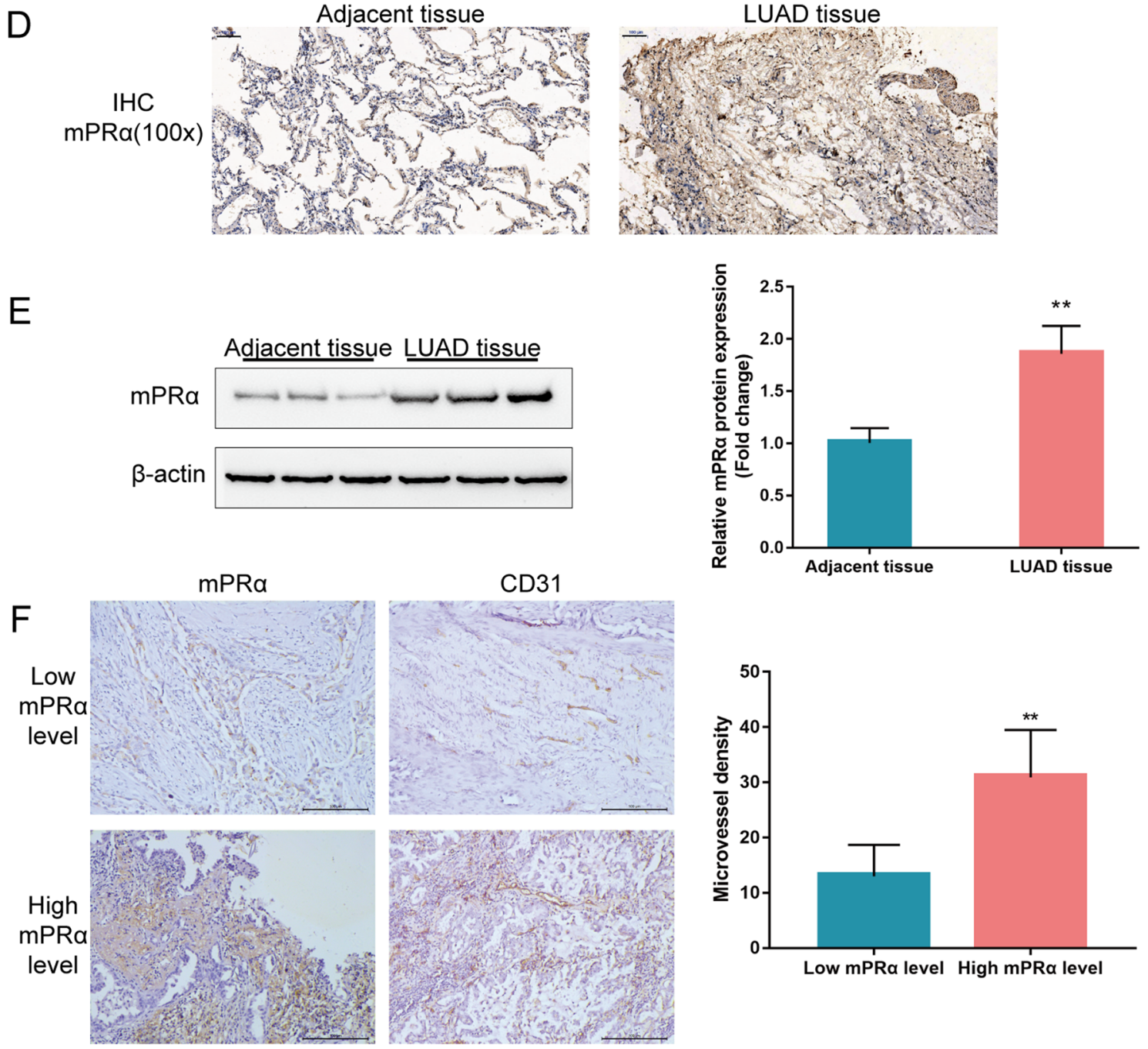

Fig. 1 (See legend on previous page.)

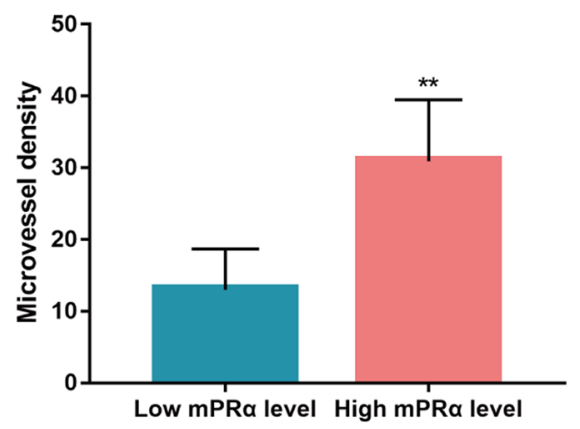


Migration and invasion determined by Transwell assays

For invasion determination, cells, $48 \mathrm{~h}$ after transfection, in the logarithmic growth phase were plated in serumfree media with mitomycin C ( $1 \mu \mathrm{g} / \mathrm{ml}$, Sigma) and added to each of the Matrigel-containing $8 \mu \mathrm{m}$ Transwell upperchamber. In the meantime, the bottom chambers were added with a medium containing $10 \%$ FBS as a chemoattractant. After a 48-h incubation, non-invasive cells on the upper chambers were discarded using cotton swabs, and invasive cells in the bottom chambers were fixed with $10 \%$ methanol and stained with $0.1 \%$ crystal violet. Invasive cells were observed and photographed under an inverted microscope (Olympus, Tokyo, Japan). Migration examination was performed similarly, albeit the upperchambers were non-Matrigel-coated.

\section{Wound healing assay}

Cells were seeded in 24-well plates at a density of $2 \times 10^{4}$ cells/well; $48 \mathrm{~h}$ after transfection, a scratch was made using a $200-\mu \mathrm{l}$ micropipette tip along the central axis of the plate. The cells were gently washed with PBS to wash away the loose cells. Then, cells were treated with $1 \mu \mathrm{g} / \mathrm{ml}$ mitomycin $\mathrm{C}$ to inhibit cell proliferation. At $0 \mathrm{~h}$ and $24 \mathrm{~h}$ of the wounding, the images were recorded, and the relative migratory distance was calculated by comparing the difference in wound width.

\section{Determination of cytokines by ELISA}

The culture medium was collected for ELISA assay using human VEGFA ELISA kits according to the manufacturer's instructions (Santa Cruz, CA, USA). The specific binding optical density was assayed immediately at $450 \mathrm{~nm}$ with a spectrophotometer (Bio-Rad Laboratories, Philadelphia, PA, USA).

\section{HUVECs tubule formation}

The knockdown or overexpression of $\mathrm{mPR} \alpha$ was generated in lung adenocarcinoma cell line A549; $48 \mathrm{~h}$ after transfection, the culture medium was collected as conditioned medium (CM) and used for HUVEC culture. HUVECs were seeded in Matrigel-coated 96-well plates at a density of $1 \times 10^{4}$ cells/well and cultured with the serum-free medium for $6 \mathrm{~h}$. Then, the cells were cultured with different $\mathrm{CM}$ as described above for $6 \mathrm{~h}$. Branch numbers or tube lengths were calculated from images in the ImageJ software.

\section{cAMP levels in culture medium}

The levels of cAMP were determined with a Detect $X^{\circledR}$

Cyclic AMP (cAMP) Direct Immunoassay kit (K019-H1; Arbor Assays, Ann Arbor, MI, USA) according to the manufacturer instructions.

\section{Establishment of Xenograft tumor model in nude mice}

A549 cells $\left(1 \times 10^{7}\right.$ cells $)$ were infected with $\mathrm{mPR} \alpha$ knockdown or overexpression lentivirus (obtained from GeneChem, Shanghai) and subcutaneously injected to the left flank of BALB/c nude mice (Hunan SJA Laboratory Animal Co., LTD, Changsha, China). Tumor volume was monitored once every three days for 21 days. On day 21, all animals were sacrificed, and the tumor tissues were collected for weight, HE staining, IHC staining, and immunoblotting analysis. All animal procedures gained the approval of Xiangya Hospital of Central South University Ethics Committee.

\section{Data processing and statistical analysis}

All data were processed using GraphPad software (San Diego, CA, USA) and expressed as mean \pm standard deviation (SD) from three independent experiments. The Shapiro-Wilks test was used to explore whether data are normally distributed and determine a parametric or nonparametric statistical approach. Kruskal-Wallis test was used for non-parametric statistical analysis. Differences between two groups were assessed by Student's $t$-test. Differences among more than two groups were assessed by a one-way ANOVA followed turkey post-hoc test. Data with $P$ values $<0.05$ were considered significant.

\section{Results}

mPRa expression and MVD within tissue samples

Before investigating the specific effects of $m P R \alpha$ on LUAD carcinogenesis, the study first confirmed the expression level of $\mathrm{mPR} \alpha$ in tissue samples. According to TCGA data, mPR $\alpha$ mRNA expression seems to be upregulated within LUAD tissue samples $(n=483)$ compared to that in noncancerous tissue samples $(n=347)$, while there is no statistical difference (Fig. 1A). However, higher expression $\mathrm{mPR} \alpha$ is associated with a worse overall survival rate in TCGA-LUAD (Fig. 1B). Next, the mRNA expression of mPR $\alpha$ was determined in collected

(See figure on next page.)

Fig. 2 mPRa activates CAMP/JAK/STAT3 signaling pathway in LUAD cells A549 and PC-9 cells were transfected with si-mPRa or mPRa and examined for (A) CAMP concentrations using a CAMP Direct Immunoassay kit; B VEGF concentrations using ELISA; $\mathbf{C}$ the protein levels of p-STAT3, STAT3, VEGF, and HIF1a. Next, A549 and PC-9 cells were transfected with mPRa in the presence or absence of STAT3 inhibitor Stattic (5 $\mu \mathrm{M}$ for $24 \mathrm{~h})$ and examined for (D) VEGF concentrations using ELISA and $\mathbf{E}$ the protein levels of $\mathrm{p}$-STAT3, STAT3, VEGF, and HIF1a. ${ }^{*} P<0.05,{ }^{* *} P<0.01$, compared to si-NC; $\# P<0.05, \# \# P<0.01$, \#\#\#P<0.005 compared to NC group; $\$ P<0.01$, compared to $\mathrm{mPRa}$ 


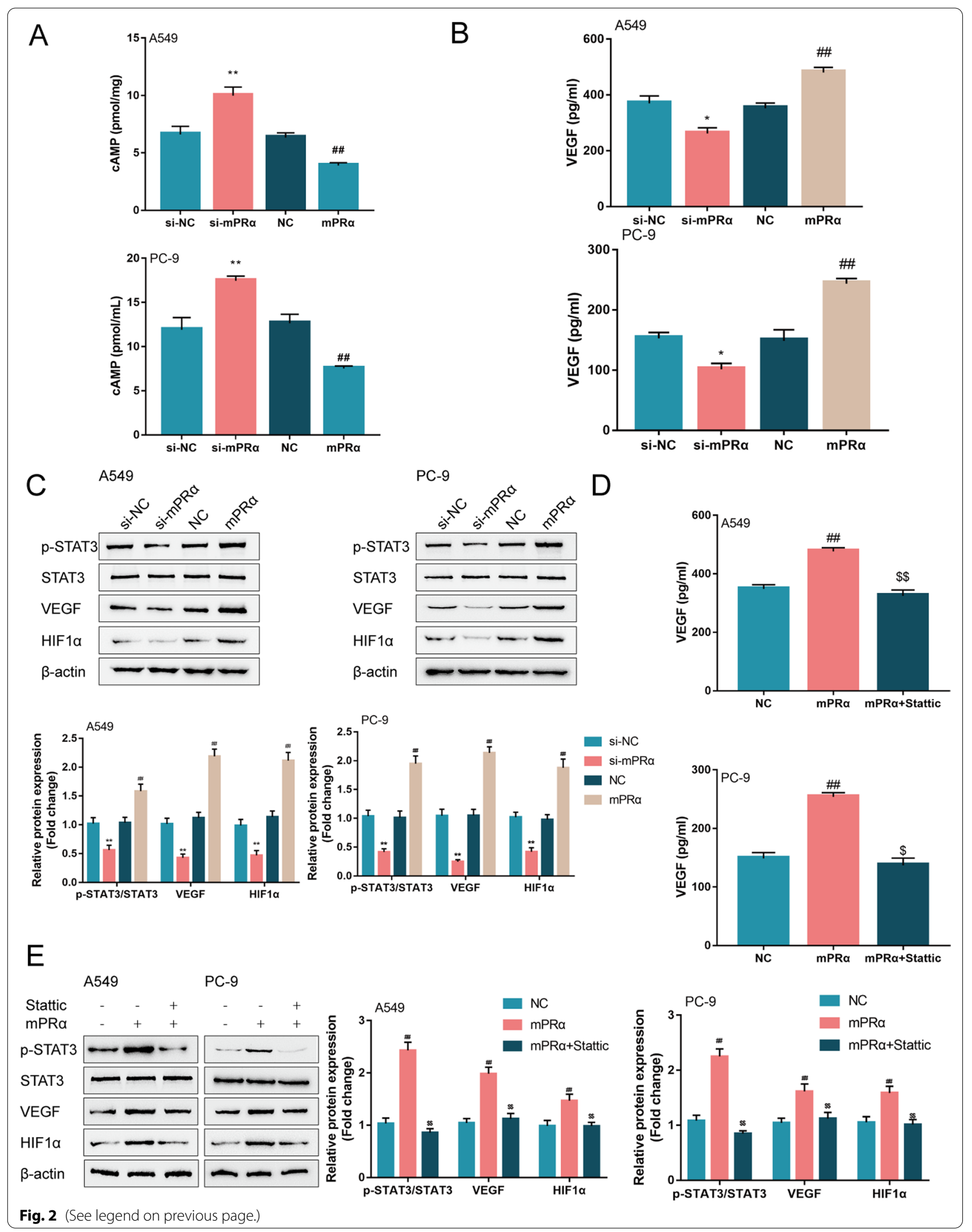




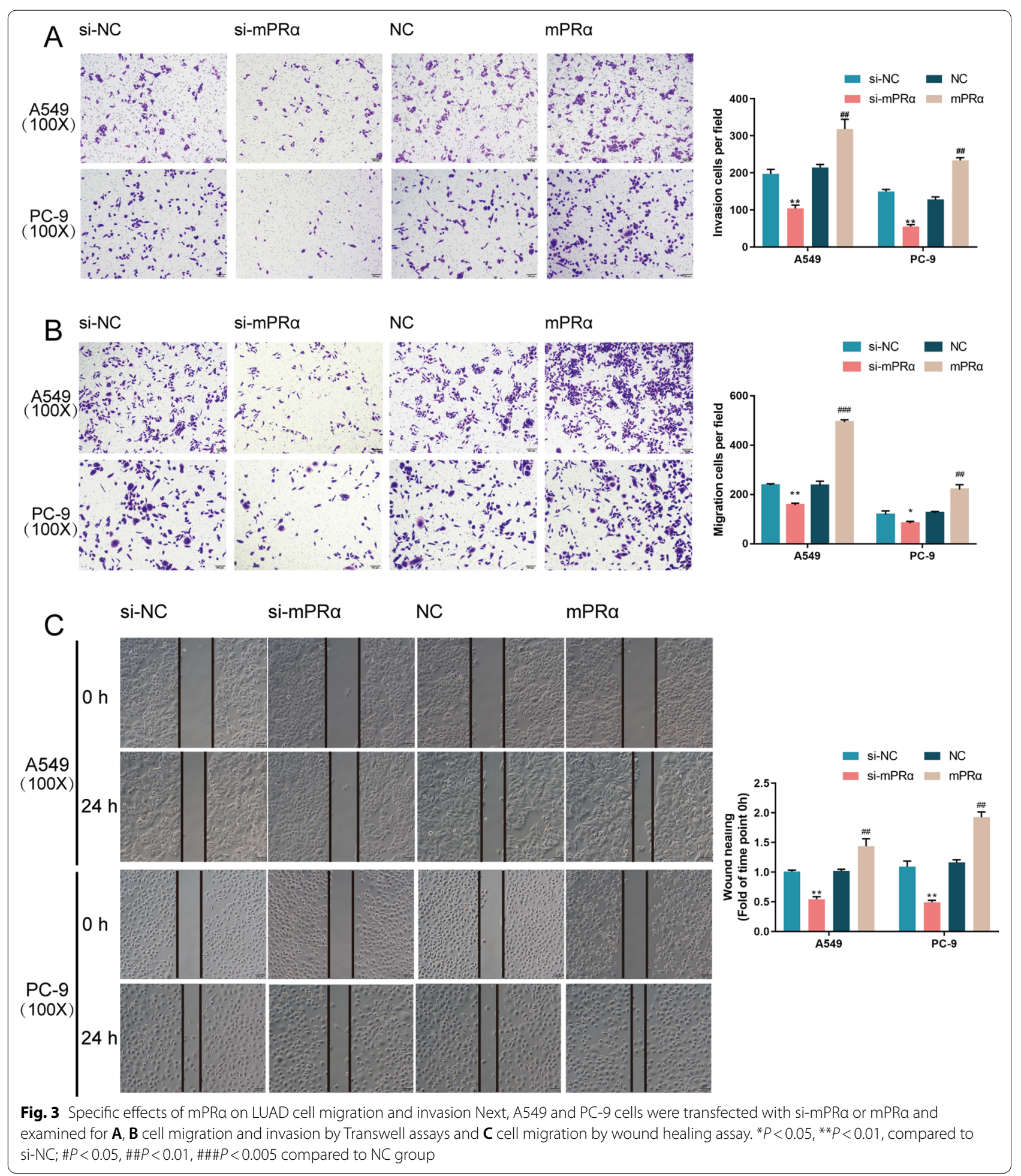


20 paired LUAD and adjacent noncancerous tissue samples using real-time PCR; consistent with online data, the expression of $\mathrm{mPR} \alpha$ showed markedly increased within LUAD tissue samples than that in noncancerous tissue samples (Fig. 1C). As revealed by IHC staining, the protein content of $\mathrm{mPR} \alpha$ was higher in LUAD tissue sections than that in noncancerous tissue sections (Fig. 1D). The Immunoblotting assay consistently indicated that the protein level of mPR $\alpha$ was increased in LUAD tissues compared to that in noncancerous tissues (Fig. 1E). As we presumed $\mathrm{mPR} \alpha$ might affect angiogenesis in LUAD, MVD in LUAD tissues with different mPR $\alpha$ was calculated, and the result revealed that MVD is significantly higher in LUAD tissues with a higher $\mathrm{mPR} \alpha$ level (Fig. 1F). These data suggest that mPRoupregulation in LUAD might have an essential effect on angiogenesis in LUAD tissues.

\section{mPRa activates CAMP/JAK/STAT3 signaling pathway in LUAD cells}

As we have mentioned, in low oxygen conditions, tumor cells are able to secrete some angiogenesis factors like VEGF into the tumor microenvironment, subsequently enhancing the angiogenesis under hypoxia [18, 35]. Besides, after STAT3 activation, HIF1 $\alpha$-induced VEGF release was increased [21]. Thus, the study generated mPR $\alpha$ knockdown or overexpression in two LUAD cell lines, A549 and PC-9, by transducing siRNA for mPR $\alpha$ $(\mathrm{si}-\mathrm{mPR} \alpha)$ or $\mathrm{mPR} \alpha$-overexpressing vector $(\mathrm{mPR} \alpha)$ and detected the effects of mPR $\alpha$ on cAMP/JAK/STAT3 signaling pathway and the content of HIF1 $\alpha$ and VEGF, using real-time PCR (Additional file 1: Fig. S1A) and Immunoblotting (Additional file 1: Fig. S1B). In both cell lines, $\mathrm{mPR} \alpha$ knockdown significantly increased the cAMP concentrations, reduced the VEGF concentrations, decreased the ratio of p-STAT3/STAT3, and decreased the protein levels of VEGF and HIF1 $\alpha$ (Fig. 2A-C); in contrast, mPR $\alpha$ overexpression exerted opposite effects by decreasing the concentrations of cAMP, increasing the concentrations of VEGF, increasing the ratio of p-STAT3/STAT3, and increasing the protein levels of VEGF and HIF1 $\alpha$ (Fig. 2A-C). For investigating whether $\mathrm{mPR} \alpha$ exerts its effects through STAT3 signaling, the study transfected A549 and PC-9 cells with $\mathrm{mPR} \alpha$ with or without STAT3 inhibitor Stattic, and examined the same indexes. As shown in Fig. 2D, E, mPR $\alpha$ overexpression-induced increases in VEGF concentrations, p-STAT3/STAT3 ratio, and the protein levels of VEGF and HIF1 $\alpha$ were significantly decreased by STAT3 inhibitor Stattic. Thus, based on these data, we speculate that $\mathrm{mPR} \alpha$ might activate the STAT3 signaling, subsequently promoting HIF1 $\alpha$-induced VEGF release and angiogenesis under hypoxia.

\section{mPRa promoted LUAD cells invasion, migration, and tumor growth}

After confirming VEGF upregulated by $\mathrm{mPR} \alpha$ in LUAD tissues, we evaluated the capacity of cells to migrate and invade, which could be promoted by VEGF. Based on both Transwell and Wound healing assays, mPR $\alpha$ knockdown significantly inhibited, while $\mathrm{mPR} \alpha$ overexpression promoted the cell migration of both A549 and PC-9 cell lines (Fig. 3A and C). Similarly, mPR $\alpha$ knockdown significantly inhibited, while $\mathrm{mPR} \alpha$ overexpression promoted the cell invasion of both A549 and PC-9 cell lines (Fig. 3B).

Next, for investigating the in vivo effects of $\mathrm{mPR} \alpha$ on LUAD growth, A549 cells were infected with lentivirus containing $\mathrm{mPR} \alpha$ shRNA or overexpression fragment and used for xenograft model establishment. As shown in Fig. 4A-C, mPR $\alpha$ knockdown significantly repressed tumor growth. In contrast, $\mathrm{mPR} \alpha$ overexpression enhanced tumor growth. Correspondingly, mPR $\alpha$, ki67, PCNA, p-STAT3, VEGF and HIF1 $\alpha$ proteins also decreased within $\mathrm{mPR} \alpha$ knockdown tumors and increased within $\mathrm{mPR} \alpha$ overexpression tumors (Fig. 4D, E). These data indicate that $\mathrm{mPR} \alpha$ enhances the aggressiveness of LUAD cells.

\section{mPRa knockdown decreases hypoxia-induced HIF1a/VEGF content and LUAD cell aggressiveness}

The specific role of mPR $\alpha$ in HIF1 $\alpha$-induced VEGF release and LUAD cell aggressiveness was investigated under hypoxia. A549 and PC-9 cells were transfected with si-mPR $\alpha$ or si-NC (negative control), exposed to hypoxia $\left(1 \% \mathrm{O}_{2}\right)$ or normoxia $\left(20 \% \mathrm{O}_{2}\right)$, and examined for related indexes. Consistent with previous studies, hypoxia exposure significantly increased HIF1 $\alpha$ and VEGF protein contents and VEGF concentrations in culture medium compared to those under normoxic conditions (Fig. 5A, B). After knocking down $\mathrm{mPR} \alpha$, hypoxia-induced increases in HIF1 $\alpha$ and VEGF levels were partially attenuated (Fig. 5A, B). As for the LUAD cell aggressiveness, hypoxia increased

\footnotetext{
(See figure on next page.)

Fig. 4 mPRa promoted LUAD cell growth in the xenograft model. A-C xenograft mouse tumor model was established in BALB/C nude mice accordingly. MPRa knockdown or overexpression lentivirus infected A549 cells were injected under the skin of the left flank of nude mice. The tumor volume $\mathbf{B}$ was measured every 3 days for 21 days; on day 21, mice were sacrificed, and the tumor weight was measured (C); $\mathbf{D}$ the protein levels of mPRa, ki67, and PCNA in tumor tissues were examined using IHC staining. $\mathbf{E}$ The protein levels of mPRa, PCNA, p-STAT3, STAT3, VEGF, and HIF1a in tumor tissues were examined using Immunoblotting. ${ }^{*} P<0.01$, compared to si-NC. \#\# $P<0.01$, \#\#\# $P<0.005$, compared to NC
} 

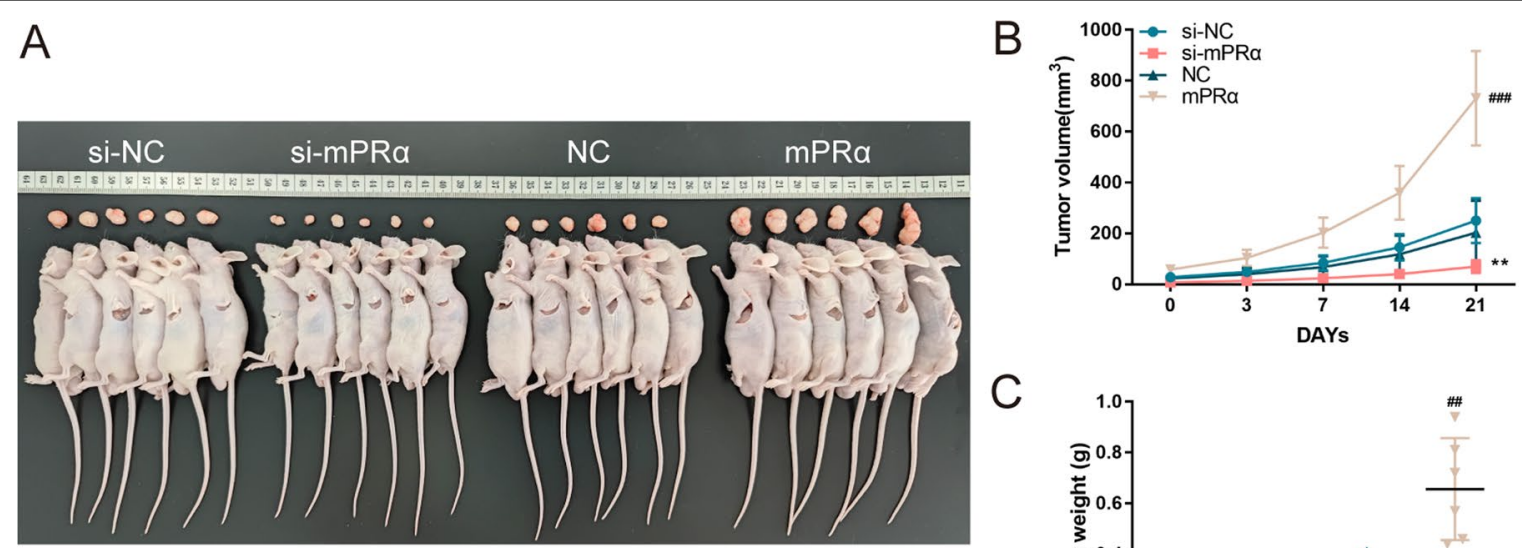

C
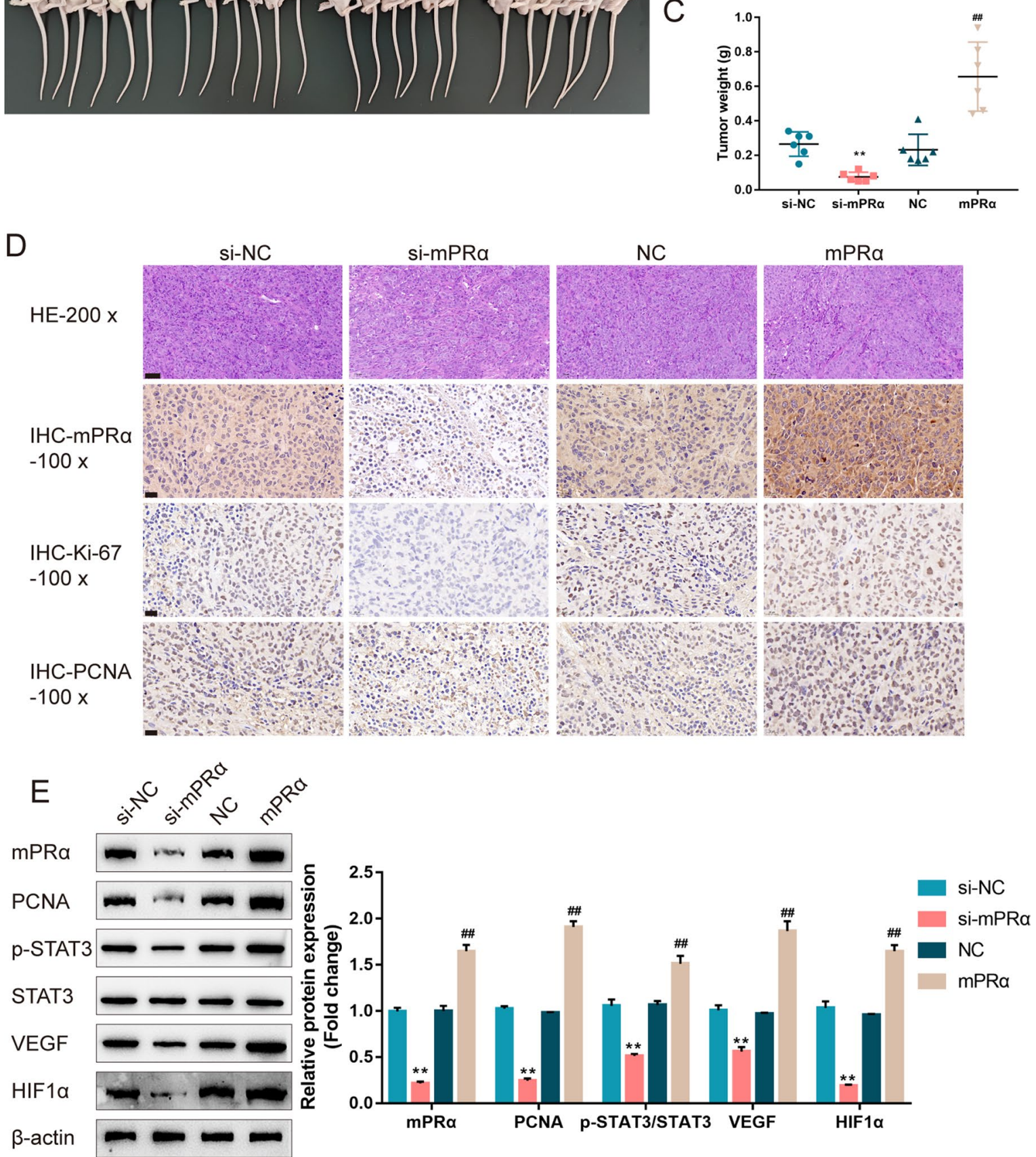

Fig. 4 (See legend on previous page.) 
the capacity of these two cell lines to migrate and to invade (Fig. 5C-E), while $\mathrm{mPR} \alpha$ knockdown inhibited hypoxiainduced LUAD cell migration and invasion (Fig. 5C-E).

\section{mPRa enhances the tube formation and migration capacity of HUVECs}

Since $\mathrm{mPR} \alpha$ knockdown inhibited hypoxia-induced HIF1 $\alpha$ and VEGF levels, as well as LUAD cell aggressiveness, we speculate that $\mathrm{mPR} \alpha$ might also play a role in HUVEC tube formation by affecting HIF1 $\alpha$-induced VEGF release through STAT3 signaling under hypoxia.

We transfected A549 cells with si-mPR $\alpha /$ si-NC and collected the culture medium for HUVEC culture (marked as si-mPR $\alpha-C M /$ si-NC-CM in Fig. 5). We cultured HUVECs in these CMs under hypoxia and examined HUVEC migratory and tube formation capacities. As shown in Fig. 6A, $\mathrm{B}$, si-mPR $\alpha-\mathrm{CM}$ culture significantly inhibited HUVEC migration and tube formation under hypoxia. Moreover, under hypoxia, VEGF release into the culture medium was reduced by si-mPR $\alpha-\mathrm{CM}$ (Fig. $6 \mathrm{C}$ ). These data indicate that $\mathrm{mPR} \alpha$ affects HIF1 $\alpha$-induced VEGF release into the tumor microenvironment, modulating hypoxia-induced angiogenesis in LUAD.

Next, we transfected A549 cells with $\mathrm{mPR} \alpha / \mathrm{NC}$ and collected the culture medium for HUVEC culture (marked as $\mathrm{NC}-\mathrm{CM} / \mathrm{mPR} \alpha-\mathrm{CM}$ in Fig. 6). HUVECs were cultured in different CMs, exposed to hypoxia ( $1 \%$ $\mathrm{O}_{2}$ ) in the presence or absence of STAT3 inhibitor Stattic, and examined for HUVEC migratory and tube formation capacities. Figure 6D, E showed that hypoxia significantly induced HUVEC migration and tube formation, and $\mathrm{mPR} \alpha-\mathrm{CM}$ culture further enhanced the effects of hypoxia; however, treatment with Stattic significantly attenuated the inducible effects of hypoxia and $\mathrm{mPR} \alpha-\mathrm{CM}$ on HUVEC migration and tube formation. Moreover, hypoxia-induced VEGF release was further enhanced by $\mathrm{mPR} \alpha-\mathrm{CM}$ culture but reduced by Stattic treatment (Fig. 6F). These data indicate that STAT3 signaling is involved in $\mathrm{mPR} \alpha$ functions on LUAD cells and HUVECs.

\section{Discussion}

Herein, mPR $\alpha$ deregulation was observed within LUAD tissue samples. $\mathrm{mPR} \alpha$ knockdown in A549 and PC-9 cells significantly inhibited STAT3 phosphorylation, as well as HIF $1 \alpha$ and VEGF protein levels, suppressing the capacity of LUAD cells to migrate and to invade. Under the hypoxic condition, $m P R \alpha$ knockdown significantly inhibited hypoxia-induced increases in HIF1 $\alpha$ and VEGF levels, as well as LUAD cell migration and invasion. Moreover, CM derived from $\mathrm{mPR} \alpha$ knockdown A549 cells, namely si-mPR $\alpha-C M$, significantly inhibited HUVEC migration and tube formation under hypoxia.

$\mathrm{mPR} \alpha$ is frequently deregulated in many cancers. Within LUAD, online data from TCGA indicated an abnormal upregulation of mPR $\alpha$ expression in LUAD tissue samples. mPR $\alpha$ mRNA expression and protein levels were also increased in LUAD subjects. However, regarding the specific role of $\mathrm{mPR} \alpha$ in carcinogenesis, opposite results have been reported, depending on the cancer type. In glioblastoma, treatment with the specific $\mathrm{mPR} \alpha$ agonist Org OD 02-0 induced an increase in U87 and U251 cell count by promoting the capacity of cells to proliferate; in addition, this treatment significantly promoted the capacity of U87 and U251 cells to migrate and invade [15]. As for breast cancer, Org OD 02-0 treatment dramatically inhibited the death and apoptosis of cells under serum deficiency stimulation [30]. Another group also regarded $\mathrm{mPR} \alpha$ as a key marker of impaired prognosis for invasive breast cancer, and $\mathrm{mPR} \alpha$ enhanced MMP-9 expression in the process of spreading to regional lymph nodes via the PI3K/Akt pathway [12]. Reportedly, mPR $\alpha$ could promote breast cancer resistance protein (BCRP) expression via the PI3K/Akt/mTOR signaling pathway, contributing to metastasis and drug resistance [17]. Herein, we observed consistent results that $\mathrm{mPR} \alpha$ are positively correlated to CD31-MVD in LUAD tissues, indicating the carcinogenic effect of $\mathrm{mPR} \alpha$ on LUAD.

As for the involved signaling pathway, herein, we next validated the roles of $\mathrm{mPR} \alpha$ in $\mathrm{CAMP} / \mathrm{JAK} / \mathrm{STAT} 3$ signaling and related HIF1 $\alpha$-induced VEGF release. Consistent with previous studies, $\mathrm{mPR} \alpha$ overexpression significantly decreased the cAMP concentrations and increased VEGF concentrations, increased the phosphorylation of STAT3, and increased the protein levels of HIF1 $\alpha$ and VEGF. Moreover, after knocking down $\mathrm{mPR} \alpha$ in LUAD cells, the cell migration, invasion, and in vivo tumor growth were significantly inhibited, which could be explained by the changes in VEGF expression. However, mPR $\alpha$ has been reported to mediate the suppressive functions of PR [36-38], even in A549 cells [39]. These seemingly contradictory findings suggest that $\mathrm{mPR} \alpha$ might function in different ways in LUAD, with the presence or absence of $\mathrm{PR}$, which needs further investigation in our future

\footnotetext{
(See figure on next page.)

Fig. 5 mPRa knockdown decreases hypoxia-induced HIF1a/NEGF content and LUAD cell aggressiveness A549 and PC-9 cells were transfected with si-mPRa or si-NC, exposed to hypoxia $\left(1 \% \mathrm{O}_{2}\right)$ or normoxia $\left(20 \% \mathrm{O}_{2}\right)$, and examined for $\mathbf{A}$ the protein levels of HIF1a and VEGF by Immunoblotting; B VEGF concentrations by ELISA; C, D cell migration and invasion by Transwell assays; $\mathbf{E}$ cell migration by wound healing assay. ${ }^{*} P<0.05,{ }^{* *} P<0.01$, compared to $20 \% \mathrm{O}_{2}$ si-NC; \#\#P<0.01, compared to $20 \% \mathrm{O}_{2}+$ si-mPRa; \&\&P<0.01, compared to $1 \% \mathrm{O}_{2}$ si-NC group
} 
A

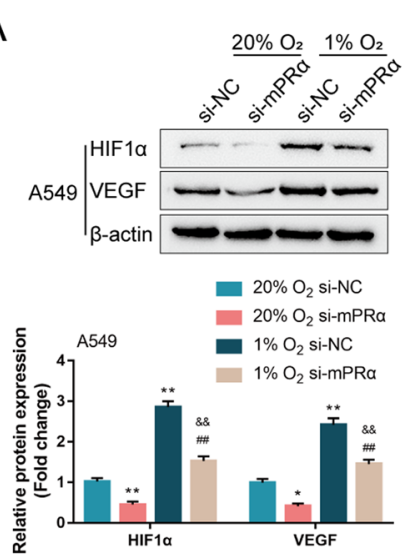

C

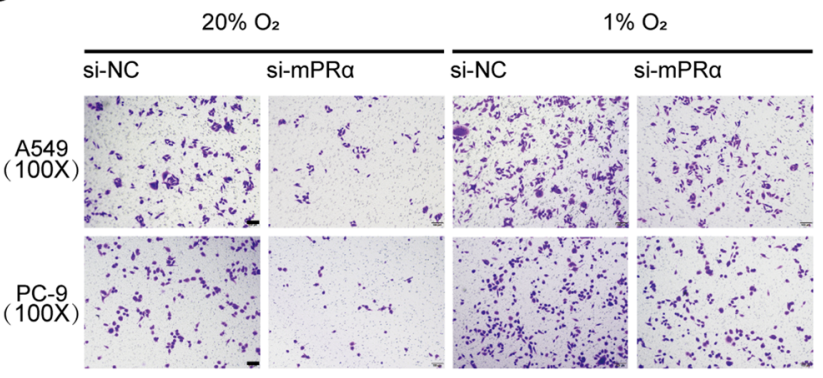

D
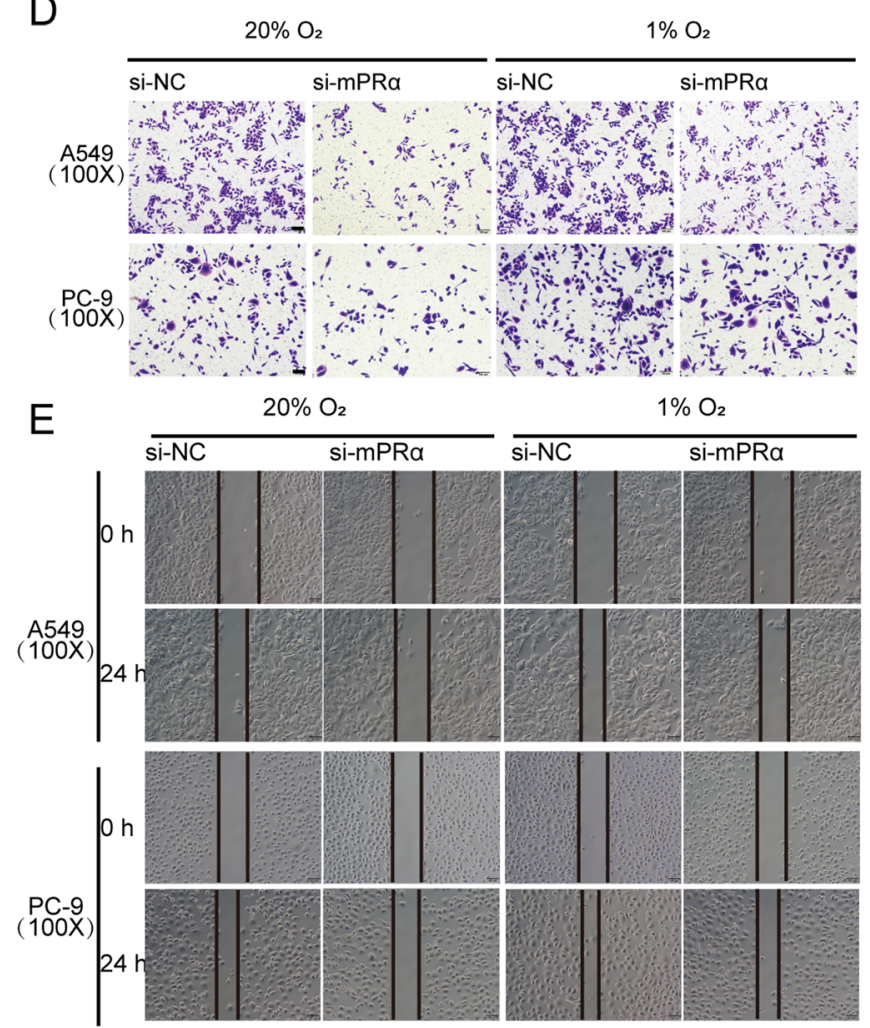

B
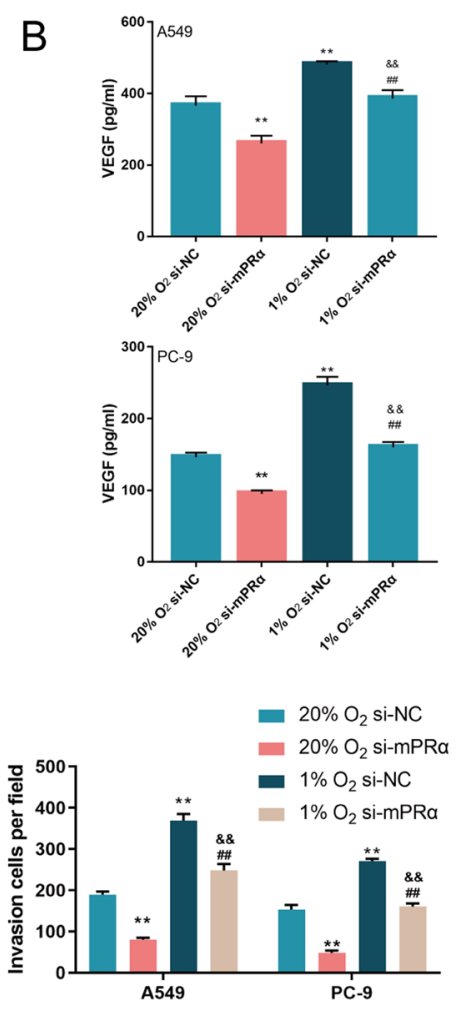

Fig. 5 (See legend on previous page.)

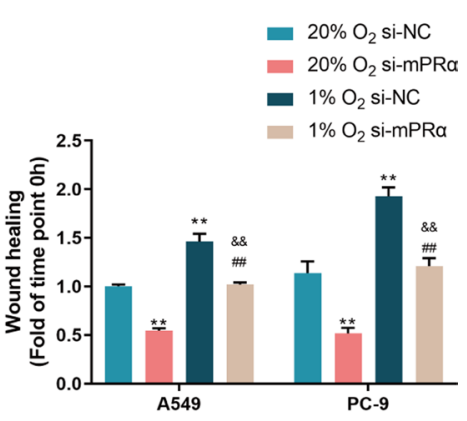




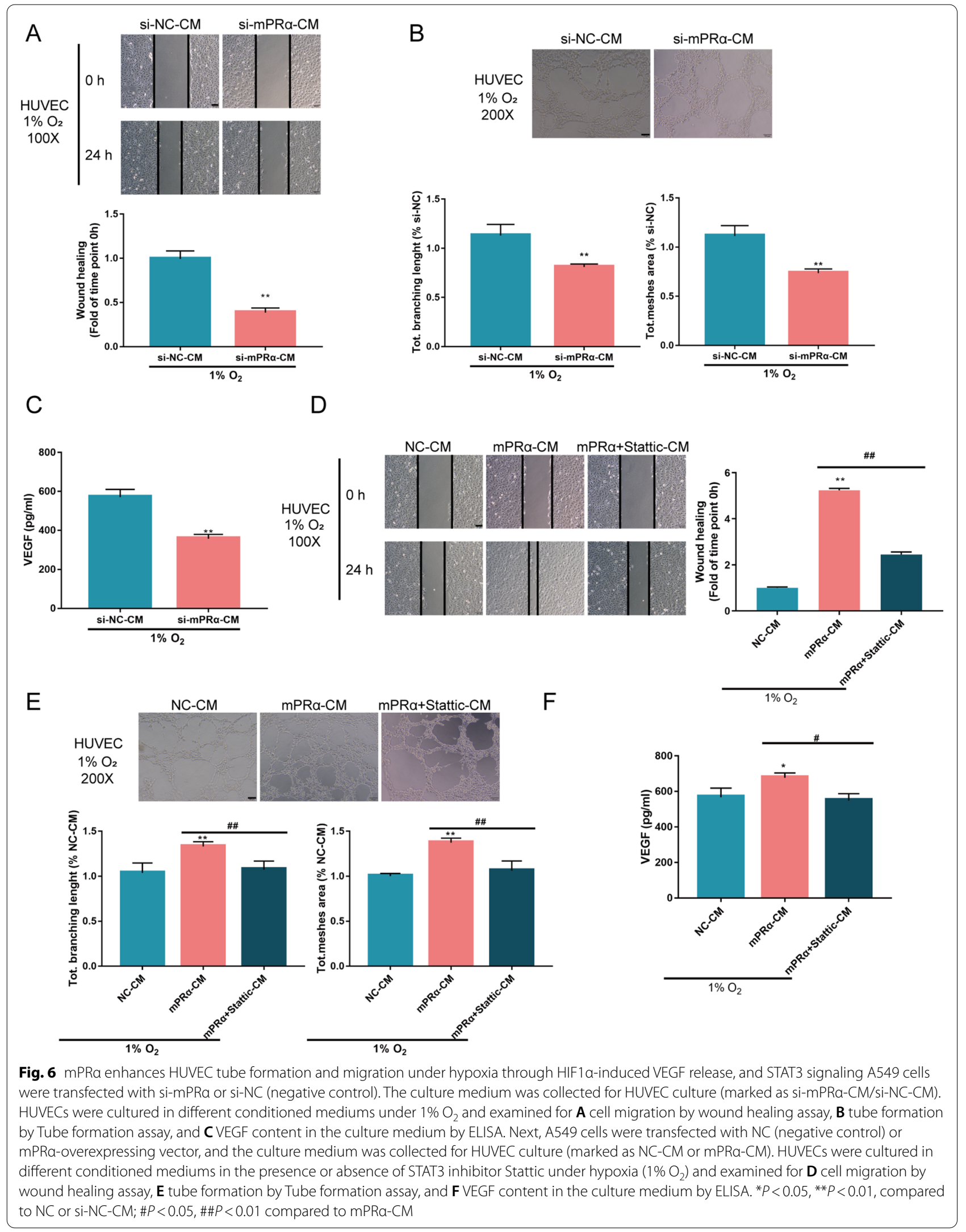


study. Moreover, in mPR $\alpha$-overexpressing LUAD cells, the treatment with STAT3 inhibitor Stattic significantly attenuated the inducible effects of $\mathrm{mPR} \alpha$ overexpression on STAT3 phosphorylation, HIF1 $\alpha$, and VEGF protein contents, as well as VEGF concentrations, suggesting that $\mathrm{mPR} \alpha$ promotes HIF1 $\alpha$-induced VEGF release through cAMP/JAK/STAT3 signaling. Receptor-related JAKs are well-known mediators of STAT3 phosphorylation for tumor development and inflammatory response $[40,41]$. Herein, $\mathrm{mPR} \alpha$ overexpression significantly promoted STAT3 phosphorylation, further confirming the oncogenic role of mPR $\alpha$ in LUAD. STAT3 is also tightly related to VEGF in cancer progression [42, 43]. STAT3 is a transcription factor that enhances the progression of urothelial cells from carcinoma in situ to invasive bladder cancer and regulates the angiogenesis of RCC (renal cell carcinoma) through upregulating HIF1 $\alpha$ and VEGF expression [44]. Moreover, under hypoxia, phosphorylated STAT3 enhances HIF $1 \alpha$ stability to increase HIF $1 \alpha-$ mediated VEGF secretion, promoting angiogenesis in renal carcinoma and liver cancer $[45,46]$. Herein, $\mathrm{mPR} \alpha$ overexpression increased HIF1 $\alpha$ and VEGF protein levels and VEGF concentrations in culture medium, suggesting the potential role of $\mathrm{mPR} \alpha$ in hypoxia-induced angiogenesis in LUAD.

Tumor micro-environment hypoxia shows to be closely related to tumor development [47]. Oxygen homeostasis is directly regulated via HIF $1 \alpha$; following a shift to a lowoxygen environment, HIF $1 \alpha$ is stabilized and subsequently translocated into the nucleus. Nuclear-translocated HIF1 $\alpha$ leads to the expression of some genes, including VEGF [48]. VEGF is a mitogen for vascular endothelial cells and several other cell types, eliciting a pronounced angiogenic response [49]. In LUAD, miR-204 targets JAK2 to inhibit JAK/STAT3 signaling, subsequently decreasing the mRNA and protein expression of HIF1 $\alpha$ and VEGF within LUAD A549 cells; conditioned medium from miR-204 overexpressed A549 cells obviously decreased the cumulative tube length and migratory ability of HUVECs [50]. Herein, hypoxia significantly increased HIF $1 \alpha$ and VEGF protein contents and promoted LUAD cell migration and invasion, which were all remarkably reversed by $m P R \alpha$ knockdown. Moreover, hypoxia also enhanced the migratory ability and tube formation capacity of HUVECs, which showed to be reversed by the incubation with the conditioned medium derived from mPR $\alpha$ knocked-down A549 cells; these findings indicate that $\mathrm{mPR} \alpha$ knockdown could reduce HIF1 $\alpha$ induced VEGF secretion into tumor microenvironment, therefore impairing hypoxia-induced angiogenesis in HUVECs. Furthermore, conditioned medium derived from mPR $\alpha$-overexpressing A549 cells enhanced the effects of hypoxia on HUVEC angiogenesis and VEGF content in the culture medium, which were reversed by STAT3 inhibitor
Stattic, indicating that STAT3 signaling is involved in mPR $\alpha$ effects on LUAD cells and HUVECs.

In conclusion, we demonstrated that in LUAD cells, highly expressed $\mathrm{mPR} \alpha$ enhances the activation of cAMP/ JAK/STAT3 signaling and increases HIF $1 \alpha$-induced VEGF secretion into the tumor microenvironment, promoting HUVEC migration and tube formation under hypoxia.

\section{Supplementary Information}

The online version contains supplementary material available at https://doi. org/10.1186/s12967-022-03270-5.

Additional file 1: Table S1. the sequence of primers, siRNA and plasmid construction.

Additional file 2: Figure S1. mPRa knockdown or overexpression generated in two LUAD cell lines, A549 and PC-9, by the transfection of siRNA for mPRa (si-mPRa) or mPRa-overexpressing vector (mPRa), as confirmed by (A) real-time PCR and (B) Immunoblotting. ${ }^{* *} P<0.01$, compared to si-NC. \#\# $\mathrm{P}<0.01$, compared to NC.

\section{Authors' contributions}

CQ and $X Z$ : conception and design of the study. $X J$ and $X Z$ : acquisition data and experimental verification. DZY: analysis and interpretation of data. $\mathrm{CQ}$ and $\mathrm{XZ}$ : drafting the article. All authors read and approved the final manuscript.

\section{Funding}

This study was supported by the Natural Science Youth Foundation of Hunan Province and Natural Science Foundation of Hunan Province, China (2021JJ41036)

Availability of data and materials

All datasets generated for this study are included in the article.

\section{Declarations}

Ethics approval and consent to participate

Animals: The procedures were approved by the Animal Research Ethics Committee of the Xiangya Hospital of Central south university (No.202009804).

Consent for publication

Not applicable.

Competing interests

None.

\section{Author details}

${ }^{1}$ Department of Geriatrics, Respiratory Medicine, Xiangya Hospital, Central South University, Changsha, Hunan, China. ${ }^{2}$ National Clinical Research Center for Geriatric Disorders, Xiangya Hospital, Central South University, Changsha, China.

Received: 30 August 2021 Accepted: 22 January 2022

Published online: 05 February 2022

References

1. Torre LA, Siegel RL, Jemal A. Lung cancer statistics. Adv Exp Med Biol. 2016;893:1-19.

2. Testa U, Castelli G, Pelosi E. Lung cancers: molecular characterization, clonal heterogeneity and evolution, and cancer stem cells. Cancers (Basel). 2018. https://doi.org/10.3390/cancers10080248.

3. Barta JA, Powell CA, Wisnivesky JP. Global epidemiology of lung cancer. Ann Glob Health. 2019. https://doi.org/10.5334/aogh.2419. 
4. Pesch B, et al. Cigarette smoking and lung cancer-relative risk estimates for the major histological types from a pooled analysis of case-control studies. Int J Cancer. 2012;131(5):1210-9.

5. Samet JM, et al. Lung cancer in never smokers: clinical epidemiology and environmental risk factors. Clin Cancer Res. 2009;15(18):5626-45.

6. Devesa SS, et al. International lung cancer trends by histologic type: male:female differences diminishing and adenocarcinoma rates rising. Int J Cancer. 2005;117(2):294-9.

7. Radkiewicz C, et al. Sex and survival in non-small cell lung cancer: a nationwide cohort study. PLoS ONE. 2019;14(6): e0219206.

8. Pinto JA, et al. Gender and outcomes in non-small cell lung cancer: an old prognostic variable comes back for targeted therapy and immunotherapy? ESMO Open. 2018;3(3): e000344.

9. Kawai $\mathrm{H}$, et al. Estrogen receptor alpha and beta are prognostic factors in non-small cell lung cancer. Clin Cancer Res. 2005;11(14):5084-9.

10. Bogush TA, et al. Estrogen receptors, antiestrogens, and non-small cell lung cancer. Biochemistry (Mosc). 2010;75(12):1421-7.

11. Huang JW, et al. Effects of estrogen-related receptor alpha (ERRalpha) on proliferation and metastasis of human lung cancer A549 cells. J Huazhong Univ Sci Technol Med Sci. 2014:34(6):875-81.

12. Wu X, et al. Breast cancer invasion and metastasis by mPRalpha through the PIJK/Akt signaling pathway. Pathol Oncol Res. 2016;22(3):471-6.

13. Charles NJ, Thomas P, Lange CA. Expression of membrane progesterone receptors (MPR/PAQR) in ovarian cancer cells: implications for progesterone-induced signaling events. Horm Cancer. 2010;1 (4):167-76.

14. Valadez-Cosmes P, et al. Expression and hormonal regulation of membrane progesterone receptors in human astrocytoma cells. J Steroid Biochem Mol Biol. 2015;154:176-85.

15. Gonzalez-Orozco JC, et al. Activation of membrane progesterone receptor-alpha increases proliferation, migration, and invasion of human glioblastoma cells. Mol Cell Endocrinol. 2018;477:81-9.

16. Dressing $G E$, Thomas $P$. Identification of membrane progestin receptors in human breast cancer cell lines and biopsies and their potential involvement in breast cancer. Steroids. 2007;72(2):111-6.

17. Zhang J, et al. Rapamycin antagonizes BCRP-mediated drug resistance through the PI3K/Akt/mTOR signaling pathway in mpra-positive breast cancer. Front Oncol. 2021;11:608570.

18. Folkman J. Tumor angiogenesis: therapeutic implications. N Engl J Med. 1971;285(21):1182-6.

19. Eberhard $\mathrm{A}$, et al. Heterogeneity of angiogenesis and blood vessel maturation in human tumors: implications for antiangiogenic tumor therapies. Cancer Res. 2000;60(5):1388-93.

20. Liu F, et al. Low-dose cadmium upregulates VEGF expression in lung adenocarcinoma cells. Int J Environ Res Public Health. 2015;12(9):10508-21.

21. Gariboldi MB, Ravizza R, Monti E. The IGFR1 inhibitor NVP-AEW541 disrupts a pro-survival and pro-angiogenic IGF-STAT3-HIF1 pathway in human glioblastoma cells. Biochem Pharmacol. 2010;80(4):455-62.

22. Zhang $\mathrm{Q}$, et al. C-X-C motif chemokine receptor 4 promotes tumor angiogenesis in gastric cancer via activation of JAK2/STAT3. Cell Biol Int. 2017:41(8):854-62.

23. Niu G, et al. Signal transducer and activator of transcription 3 is required for hypoxia-inducible factor-1alpha RNA expression in both tumor cells and tumor-associated myeloid cells. Mol Cancer Res. 2008:6(7):1099-105.

24. Thomas P. Rapid steroid hormone actions initiated at the cell surface and the receptors that mediate them with an emphasis on recent progress in fish models. Gen Comp Endocrinol. 2012;175(3):367-83.

25. Dressing $\mathrm{GE}$, et al. Progestin signaling through mPRalpha in Atlantic croaker granulosa/theca cell cocultures and its involvement in progestin inhibition of apoptosis. Endocrinology. 2010;151(12):5916-26.

26. Karteris $\mathrm{E}$, et al. Progesterone signaling in human myometrium through two novel membrane $G$ protein-coupled receptors: potential role in functional progesterone withdrawal at term. Mol Endocrinol. 2006;20(7):1519-34

27. Thomas P. Characteristics of membrane progestin receptor alpha (mPRalpha) and progesterone membrane receptor component 1 (PGMRC1) and their roles in mediating rapid progestin actions. Front Neuroendocrinol. 2008:29(2):292-312.

28. Thomas $\mathrm{P}$, et al. Steroid and $\mathrm{G}$ protein binding characteristics of the seatrout and human progestin membrane receptor alpha subtypes and their evolutionary origins. Endocrinology. 2007;148(2):705-18.
29. Sleiter $\mathrm{N}$, et al. Progesterone receptor $\mathrm{A}$ (PRA) and PRB-independent effects of progesterone on gonadotropin-releasing hormone release. Endocrinology. 2009;150(8):3833-44.

30. Dressing GE, et al. Membrane progesterone receptors (mPRs) mediate progestin induced antimorbidity in breast cancer cells and are expressed in human breast tumors. Horm Cancer. 2012;3(3):101-12.

31. Pang $Y$, Thomas P. Progesterone signals through membrane progesterone receptors (mPRs) in MDA-MB-468 and mPR-transfected MDA-MB-231 breast cancer cells which lack full-length and $\mathrm{N}$-terminally truncated isoforms of the nuclear progesterone receptor. Steroids. 2011;76(9):921-8

32. Krietsch T, et al. Human homologs of the putative $G$ protein-coupled membrane progestin receptors (mPRalpha, beta, and gamma) localize to the endoplasmic reticulum and are not activated by progesterone. Mol Endocrinol. 2006;20(12):3146-64.

33. Camilletti MA, et al. Participation of membrane progesterone receptor alpha in the inhibitory effect of progesterone on prolactin secretion. J Neuroendocrinol. 2018;30(9): e12614.

34. Liu Y, et al. LncRNA TINCR/miR-31-5p/C/EBP-alpha feedback loop modulates the adipogenic differentiation process in human adipose tissue-derived mesenchymal stem cells. Stem Cell Res. 2018:32:35-42.

35. Rockwell S, Knisely JP. Hypoxia and angiogenesis in experimental tumor models: therapeutic implications. EXS. 1997;79:335-60.

36. Zhou L, et al. Progesterone suppresses triple-negative breast cancer growth and metastasis to the brain via membrane progesterone receptor alpha. Int J Mol Med. 2017:40(3):755-61.

37. Zuo L, LiW, You S. Progesterone reverses the mesenchymal phenotypes of basal phenotype breast cancer cells via a membrane progesterone receptor mediated pathway. Breast Cancer Res. 2010;12(3):R34.

38. Xie M, et al. Progesterone and Src family inhibitor PP1 synergistically inhibit cell migration and invasion of human basal phenotype breast cancer cells. Biomed Res Int. 2015;2015: 426429.

39. Xie $\mathrm{M}$, et al. Progesterone inhibits the migration and invasion of A549 lung cancer cells through membrane progesterone receptor alphamediated mechanisms. Oncol Rep. 2013;29(5):1873-80.

40. Wake MS, Watson CJ. STAT3 the oncogene-still eluding therapy? FEBS J. 2015:282(14):2600-11.

41. Yu H, et al. Revisiting STAT3 signalling in cancer: new and unexpected biological functions. Nat Rev Cancer. 2014;14(11):736-46.

42. Zhao D, et al. VEGF drives cancer-initiating stem cells through VEGFR-2/Stat3 signaling to upregulate Myc and Sox2. Oncogene. 2015;34(24):3107-19.

43. Wu X, et al. Silencing of Eag1 gene inhibits osteosarcoma proliferation and migration by targeting STAT3-VEGF pathway. Biomed Res Int. 2015;2015: 617316

44. Santoni M, et al. Role of STAT3 pathway in genitourinary tumors. Future Sci OA. 2015;1(3):FSO15.

45. Jung JE, et al. STAT3 is a potential modulator of HIF-1-mediated VEGF expression in human renal carcinoma cells. FASEB J. 2005;19(10):1296-8.

46. Carbajo-Pescador $\mathrm{S}$, et al. Inhibition of VEGF expression through blockade of Hif1 a and STAT3 signalling mediates the anti-angiogenic effect of melatonin in HepG2 liver cancer cells. Br J Cancer. 2013;109(1):83-91.

47. Albini A, et al. Cancer prevention by targeting angiogenesis. Nat Rev Clin Oncol. 2012:9(9):498-509.

48. Vaupel P. The role of hypoxia-induced factors in tumor progression. Oncologist. 2004;9(Suppl 5):10-7.

49. Ferrara N, Gerber HP, LeCouter J. The biology of VEGF and its receptors. Nat Med. 2003;9(6):669-76.

50. Liu X, et al. MicroRNA-204 deregulation in lung adenocarcinoma controls the biological behaviors of endothelial cells potentially by modulating Janus kinase 2-signal transducer and activator of transcription 3 pathway. IUBMB Life. 2018;70(1):81-91.

\section{Publisher's Note}

Springer Nature remains neutral with regard to jurisdictional claims in published maps and institutional affiliations. 